\title{
Ad-Blocking Threats on Online Advertising
}

\author{
Riris Endah Respati ${ }^{1}$, Irwansyah ${ }^{2}$ \\ \{ririsendahrespati@gmail.com ${ }^{1}$,dr.irwansyah.ma@gmail.com² ${ }^{2}$,
}

Faculty of Social and Political Sciences, Universitas Indonesia, Indonesia ${ }^{1,2}$

\begin{abstract}
Ad-blocking is the act of the user consciously avoiding online advertising by installing a computer program that can automatically block ads. If there is no advertisement displayed on a website, there is no revenue from online advertising. In 2016, estimated global loss from the use of ad-blocking was $\$ 1.4$ billion. The purpose of this research is to provide input to the advertisers about the threat of ad-blocking by using a qualitative approach with a desk review method. Several ways for advertisers, publishers, and ad networks to face ad-block is to ask website visitors to turn off ad-blocking extensions, put their websites in the white list, or disguise ad. If the online advertising world wants to succeed in fighting ad-blocking, they need to create advertisements that not disrupt users' convenience, switch to electronic word of mouth, or advertise through endorse on social media such as Instagram, Twitter, or YouTube.
\end{abstract}

Keywords: Advertising, Ad-Blocking, Industry, Threat

\section{Introduction}

Advertising is a form of marketing communication that uses various ways to have an impact on the thoughts, feelings, and behavior of the consumers [1]. Advertising is creating a value [2]. Advertising becomes the link between the seller and the consumers. Advertising in communication and information area, can act as a medium and also as a message [3]. Randall Rothenberg, president and chief executive of the Interactive Advertising Bureau (IAB), stated that for hundreds of years, advertising and marketing had been the center of delivering entertainment and services that were declared free to consumers [4]. Three things need to be considered by advertisers, and the first one is the primary purpose of advertising is to inform, awaken the emotional side, and trigger an action [2]. The second thing that must be considered is to choose the target correctly so that the intended message can be conveyed properly [2]. The third thing is to choose the right way to advertise, it can be done traditionally or in a modern style, and it must also be adjusted according to who the target will be [2].

Online advertising is an activity to attract public attention to a product or business through electronic media [1]. The basis of all online advertising and marketing is through search engine marketing, because users enter the digital world through search engines [5]. Online advertising is now a multi-billion dollar industry [6]. The purpose of advertising now is no longer selling products to consumers, but interacting with consumers and satisfying consumer needs better, compared with competitors [5]. Online advertising accelerates the transaction process between buyers and sellers [5]. There are several advantages of online advertising. The first reason is because it is easier to form brand awareness, increase the likelihood of purchases, and be able to find out the number of people who are interested in our advertisements by looking at the CTR (Click-Through Rate) [1]. Online advertising can strengthen brand perception, increase 
conversion rates, and can help achieve very specific niche targets [1]. Online advertising can achieve high segmentation capacity in the area of demographics and technology. Besaides, online advertising have the possibility to contact directly with customers, have flexibility format, low distribution costs, and the speed of implementation [1]. The forms of online advertising are display advertising or banner advertising, search advertising, social media advertising, email advertising, content advertising, and video advertising [1]. Online advertising can be in the form of writing with links, images or graphics, video ads, and pop-up window advertisements [7]. The disadvantages of online advertising are the threats of insecurity, confusion because multiple options, unstable internet speeds, "filtered" visitor, lack of marketing skill, online fraud, target buyers who do not use the internet, and users install adblock [1].

From the industry perspective, we can see it from the advertiser side and the publisher side [1]. Publishers are the ones who provide content that can attract people to come and visit [1]. Publisher offers a platform where visitors can view content as well as the advertisements [1]. Advertisers are those who have a product or message to be marketed and promoted to website visitors [1]. There is also an Ad Network, which is a company that helps advertisers to connect with several websites with the main task is to provide advertising space for advertisers from many publishers [1].

What if there is a program that can block online advertisements from advertisers? So that the ads never appear or seen at all by the target market. What would happen to the world without ads? This is what is happening in the online advertising world today, when internet users refuse to see advertisements when they are visiting a website. Internet users consciously use adblocking programs to protect themselves from all of the ads that are being directed to them. This research will explain the position and role of ad-blocking in the online advertising world, whose impact has adversely affected the advertising industry.

Henrik Aasted Sørensen, an independent software developer, based in Copenhagen, wrote the source code for Ad-block, which was the first advertisement blocking extension that was widely used in 2002 [8]. At that time, an extension to remove the ad already existed but was only based on image size [8]. Sørensen creates a more efficient approach by filtering ads based on image addresses, because ads tend to be centered on a particular address [8]. The original version of ad-block does not prevent downloading ads, but only hiding ads from the web page, according to the filters specified [8]. Unlike today's modern ad-blockers, which require users to maintain their filter list [8]. Sørensen's code is circulated from the developer to other developers [8]. In 2006, the Sørensen's code was taken by the founder of Adblock Plus, named Wladimir Palant, who began rewriting the Sørensen's code to provided that not only were ads blocked from display, but also ensured that ads were not downloaded at all [8]. Sørensen said he never made money from the original ad-block code he made [8]. Meanwhile, Adblock Plus, which is owned by a German-based company, called Eyeo, earns millions of dollars from burdening big companies like Google, Microsoft, and Amazon with considerable costs to whitelist their ads, which allows some "acceptable" ads to appears on the website's page [8].

In simple terms, ad-blocker is a tool that help people enjoy the internet without advertising [9]. Ad-blocking is an extension in the browser, VPN, or DNS solution that acts as a firewall between a web browser and all known ad servers [10]. Ad-blocking can be defined as the user's conscious action to avoid online advertising by installing computer programs that can automatically block advertisements [11]. Most ads are blocked by web browser extensions, installed by end-users [10]. The most popular ad-blocking extensions are "Adblock Plus" and "AdBlock" [10]. After the ad-blocking extension is installed, this extension will automatically effectively block ads on all websites in almost all ad formats [10]. 
Ad-blocking program or ad filtering program can help users to block or hide ads that appear and can affect the delivery of advertisements to potential users [1]. The ad-blocking technique has overgrown and chosen by many users, thereby reducing the database [1]. The use of adblockers can also reduce the potential reach of ad campaigns to targeted audience segments [12]. Ad-blocking is also increasingly known because they provide a cleaner and faster browsing experience by removing excessive and annoying ads [13]. Previously it was estimated that online advertisement would not be able to last long, and ads with content bundling methods would soon lose their importance [14].

\section{Research Method}

This study used a qualitative approach with desk a review method and also using secondary data [15]. Desk research is doing research by sitting at a desk and simply collecting various information that already exists to be combined and analyzed [16]. One way to do desk research is by online desk research, which is gathering information from websites on the internet and through search engines on the internet [16]. This research aims to improve the clarity of the concept, provide a comprehensive explanation of the idea of blocking ads, and offer solutions to problems regarding ad-block. This study also aims to describe the conditions that are happening as well as the facts about ad-blocking, which are a nuisance to online advertising. The results of this study can also be used as input to advertisers to see their opportunities in advertising in the world of online advertising. Besides, this research also provides feedback to the advertising industry about what should be done to save the future of the online advertising world, so that it is not extinct by the disruption of the emergence of the ad-blocking. If advertisers are not observant in seeing the ad-blocking phenomenon, it is not impossible and there will be no longer an advertisements in online advertising because they have been removed quickly by ad-block.

\section{Results}

Ad-blocking is generally used two techniques to remove ads from the pages of a website, by hiding ad elements or blocking access to the ad server [17]. The first way is to hide the ad elements, that can be done if a website page is a document that explains how the page will be rendered in the site browser window [17]. The site's can contain text, formatting directives, scripts, and images that make up the content and behavior of the page that will be presented to users [17]. Ad-blocking is browser-based, centered around the Document Object Model (DOM) [17]. DOM provides a structured representation of website page content along with a programming interface that allows content to be accessed and modified [17]. DOM, for example, which allows the interactive nature of pages of a website to be implemented, such as hiding and displaying parts of the website pages based on user choice, or dynamically changing the style or color of different page elements [17]. Either before or after the website page is loaded, the ad-blocker scans the website page document using the DOM to identify the content elements that contain the ad [17]. When advertising-related content is detected, the DOM programming interface is used to hide these elements from the view of website visitors [17]. The second way is by blocking access to the ad server. The page that contains the ad and contains JavaScript code is designed to contact the ad server that provides the ad content to be displayed 
[17]. The second technique used by this ad-blocker prevents the browser from contacting the ad server, thus preventing the ad from being downloaded and displayed to users [17].

The Ad-block extension has the power to control what requests are made by a website and monitor all requests made by the browser [18]. The Ad-block extension can reject any request that matches the ad entry and ad server that is blacklisted [18]. Ad-blocking can rely on a list of filters collected manually to block advertisements and trackers [13]. Ad-blocking works using a filter list, which lists the locations of known publications [19]. Each ad-blocker is driven by a filter list, which is a set of syntactic matching rules to block (or allow) the URL's loading by the browser [20]. Ad-blockers can embed filter lists as part of their implementation or enable users to load one or several public filter lists into the tool [20]. EasyList and EasyPrivacy are two of the most used filter lists for blocking advertisements and trackers [13]. EasyList contains more than 63 thousand filter rules, and EasyPrivacy contains more than 13 thousand filter rules [13]. EasyList includes thousands of regular expressions that have several states that refer to URLs and other regulations that relate to elements on the website's page [19].

A group of volunteers manages the filter through informal crowdsourced who get input from users [13]. The extension periodically always takes the latest version from the filter list, and it applies to the entire set of filters at each visit [13]. The filter list used by ad-blocking contains two types of rules in the form of regular expressions [13]. First, HTTP filter rules frequently block HTTP requests to retrieve ads from a known third-party ad domains [13]. Second, HTML filter rules frequently hide HTML elements that contain advertisements [13].

URL filters will be applied to every outgoing request, and requests that match the ad database filter will be used [19]. Filter hiding or blocking ad elements is used to the page of the destination website, and items that match any ad filters will be hidden [19]. Ad-blocker checks all elements and blocks elements that contain advertisements [21]. When ads are blocked, the space on the website page is now left blank because there are no more ads [18]. Ad-block extensions generally change editorial content to occupy the space emptied by ads using CSS styling [18]. Content is adjusted to fill the space left by blocked ads [18]. From the perspective of users who visiting the website, the result is a redesign of cleaner website pages, and the pages can load faster because no ads are being transferred [18]. While from the publisher's perspective, the result is the inability to monetize website users [18]. The drawback of the system with filter lists is that filter lists must continuously catch up to stay in tune with the human categorization of advertisements [19].

The rise of ad-blocking causes damage that is more than just financial, but also existential [22]. Ad-blocking arises when the media industry has established a new revenue model to move forward, and it seems that publishers ignore the fact that print and digital advertising are different [22]. Print advertisements are less likely to be avoided than broadcast-based ads [21]. Digital advertising is not static, but it blinks, can follow, is annoying, and readers can do what they could not do before in print advertising, as an example is to remove it [22]. People feel annoyed while surfing the website and bothered by pop-ups ad that suddenly appear and cover the content of the website, or an unexpected sounds from advertisements or animated banners that are flashing [21]. A person's motivation to use internet blocking can be divided into several reasons [23]. Out of $30 \%$ have reasons for being exposed to viruses and malware. Out of $29 \%$ have the reason that advertisements are displayed to be annoying. Out of $16 \%$ have reason the loading time of the website is slower. Out of $14 \%$ have too many ads on website pages and $6 \%$ have privacy and threat tracking reasons by unknown parties [23]. Andrew Bosworth, vice president for Facebook's advertising and business platform said that disruptive advertising is an industry problem. The rise of ad-blocking is a strong signal that people don't want to see ads, but using ad-blocking is a terrible solution to fight the adertisement [4]. 
Here are the top five reasons why people block ads in the 2018 Global Web Index report. As $49 \%$ of users have reason that there are too many ads on the internet, $47 \%$ state that they are annoying and not in accordance with their interests, $44 \%$ state that the advertisements displayed are annoying, $39 \%$ of advertisements sometimes contain viruses and bugs, and $37 \%$ say that ads consume too much of the screen portion of a website [24]. The existence of annoying online advertising led to the birth of the evolution of techniques in the form of blocking ads [6].

Ad-blocking grows by word of mouth and also the attention of the reporting media, thereby increasing awareness of ad-blocking software [23]. Men know more about ad-blocking from the internet, news, or the media; twice as often as women [23]. While the most common way for women to know about blocking ads is derived from information through family members [23]. Out of $37 \%$ of ad-block users know about blocking ads through their friends, coworkers, or family. Out of $28 \%$ know from the internet, news, or media. Out of $23 \%$ don't remember where they know about ad-blocking and 10\% respondents know about blocking ads when searching in browser extensions tab [23].

Out of $90 \%$ of ad-blocking users have experience the ad-block wall [23]. Ad-block wall is an order to disable ad-blocking if they want to continue to visit a website [23]. As 74\% of users choose to leave the website rather than having to turn off the ad-blocking that they have, and only $26 \%$ of users are willing to disable ad-blocking to be able to continue visiting a website [23]. These numbers show that ad-block walls are an ineffective way to make internet users deactivate internet ad-blocking, even for a temporary period of time, unless the content owned by the website is precious that cannot be found elsewhere [23]. There are still some exceptions to certain advertisements from ad-blocking users that they think are tolerable or not. As $77 \%$ of ad-blocking users still tolerate some advertisements [23]. Out of 52\% of ad-blocking users rated ads with a static banner ad format to be tolerated, while $35 \%$ preferred skippable ads [23]. For $31 \%$ of users of ad-blocking, stated that they did not like the video that could not be skipped and had to be watched until finish, and $23 \%$ of users did not like video ads that were automatically played [23]. Ads with non-interrupt formats, such as banner ads, can still be accepted, while advertisements that are interrupted are the leading causes for someone to use an ad-blocking program [23].

Besides the problem of annoying advertisements, the issue of privacy threats is also a concern of internet users from the emergence of online advertising. Advertisers increase their ability to target people personally, and each individual will demand the choice to remain anonymous to protect the identity of all types of businesses from profiling internet users [25]. Internet users may not like being tracked on various types of media [25]. Privacy concerns arise because advertising has been adjusted to the specific target market [21]. Advertisers collect and use users' personal information, such as demographics, geography, habits, and buyer behavior, to optimize ad campaigns [21]. Consumers become threatened when ads become too personal and they feel that their data is being harassed. Therefore they prefer to used the ad-block [26]. The reasons above show the security issues that arise from advertising in the online advertising world can trigger security problems, especially security for personal data of internet users.

The efforts from users to avoid advertising referred to ad avoidance. Ad avoidance or avoidance of advertisements are all actions taken by media users who can differently reduce the exposure of advertising content to themselves [27]. The emergence of ad avoidance is a result of disruptive forms of online advertising and forcing visitors of a website to see these ads without approval. All types of broadcast media can be affected by the avoidance of advertisements [11]. In recent years, the avoidance of advertisements has mostly come from the online realm [11]. The concept of advertising avoidance was put forward by Cho and Cheon in 2004, which linked cognitive, affective, and attitude aspects in response to the stimulation of 
advertising [11]. From the cognitive side, it is the consumer's belief to ignore advertising. From the affective side, this is related to consumer feelings or emotional reactions to hate advertising. In terms of behavior, it is consumers' actions to avoid objects by installing ad-block [28]. Avoidance behavior towards advertising can be done in passively or actively [29]. Passive advertising avoidance done with little effort, by not looking at the ad or waiting for the ad to disappear [29]. While the avoidance of advertisements in an effective relates to consumers who are trying to escape from ad exposure by closing ads, leaving websites, and using ad-block [29]. Avoidance of advertisements in an effective way can only be done in the digital era as it is today, where internet users have control and choice over what they want to see or not.

Research using Artificial Intelligence shows the results that half of all advertisements displayed online, can be categorized as aggressive or substandard [30]. If the ads on the internet have good quality, then blocking ads will not be as attractive as it is today [30]. Ad-blocking does not prevent the ad from being heard by the target market and it's just that the ad-blocker gives users more control to limit the number of ads viewed on a website [30]. Online advertising usually aims to attract the attention of consumers, but online advertising often diverts people from planned activities [29]. Most online advertisements are not attractive, but rather annoying, not giving information, and instead of distracting, rather than educating, and even misleading [30]. Some online advertisements come in a raiding way, and this encourages many consumers to find a way to block them [31]. The growing popularity of ad-blocking is a severe problem in the digital world [32].

The security aspect is an important concern for internet users in Indonesia. As $66 \%$ of users, using a personal browsing window that leaves no traces on the main computer they use [33]. Out of $43 \%$ users delete cookies on the main computer after they use. Out of $33 \%$ use adblocking equipment on the main computer they use. Out of 30\% use ad-blocking on their daily driver of the mobile devices and finally $22 \%$ use ad-blocking so it is not tracked on the main computer they use [33]. Out of 53\% of internet users in Indonesia, block ads using any device they have every month [24]. Indonesia is the first position country that blocks advertisements [24]. In second place are Malaysia 51\%, India 50\%, Philippines 50\%, and China 49\% [24]. The top reason for blocking ads in Indonesia is because they appear annoying [24].

For the ad-block penetration index by country and region, Indonesia ranks first with an overall value of 58\% [23]. Ireland and Greece occupy the second position, with a total cost of $39 \%$ [23]. The fourth place is Pakistan, with 32\%, while India and Sweden occupy the fifth place by $28 \%$ [23]. As $94 \%$ of mobile ad-block users globally are in the Asia-Pacific region and even have overgrown to $59 \%$ of smartphone usage in India [23]. Mobile ad-block users in the first place are India with 236 million mobile devices, China with 106 million devices, the United States with 52 million devices, Indonesia with 35 million mobile devices, and Germany with 21 million devices [23].

Globally, ad-blocking users grew $41 \%$ year on year, especially in the 2nd quarter of 2014 to the 2nd quarter of 2015 [10]. In June 2015, ad-blocking users reached 198 million active users per month who used the ad-blocking extension in their browsers [10]. Over the past seven years, the Google Chrome browser has tried to capture the market from Internet Explorer [10]. Google's primary business is from online advertising, but ironically it is also the Google Chrome browser that brings ad-blocking features to be popular in the community [10]. This is made possible by adding the ad-blocking extensions to the Google Chrome browser [10]. Users that used ad-blocking extension in Google Chrome increased by 51\% from 2014 to 2015, to an average of 126 million active users per month [10]. Ad-blocking users in the FireFox browser are around 48 million users every month, and in the Safari browser, there are approximately 9 million users every month [10]. 
The growth of users who are blocking ads, not only happens to web browsers users but also on mobile devices users. In 2016, ad-blocking users on mobile devices surged in Asia-Pacific by $40 \%$ [23]. In December 2016, there were more than 600 million devices that running adblock software globally and $62 \%$ of them were on mobile devices [23]. Total desktop and mobile usage for ad-blocking has increased from 142 million devices to 615 million from December 2015 to December 2016 [23]. The purpose of ad-blocking on mobile devices globally reached 380 million active devices as of December 2016 [23]. Then for the use of ad-blocking on the desktop, reached 236 million active devices globally until December 2016 [23].

From the ad-block user data above, it can be seen that Indonesia is the most alert country, by being the largest ad-block user in the world. Internet users in Indonesia realize that the appearance of the advertisements that begin to interfere with their activities while surfing the internet. From the behavior, we can learn which websites are most frequently visited by internet users in Indonesia and what kind of ads that appeared. While the growth of ad-block users in the world and also in Indonesia continues to grow every year, it is not impossible that Indonesia, as a massive user ad-block, will be the first country that will rarely see online advertising when surfing the internet. This has become a severe problem because it will affect the commercial and advertising industry.

The online advertising industry considers ad-blocking as a serious severe threat to their business model [13]. The development of the advertisement blocking phenomenon has real economic consequences [34]. In digital advertising ecosystem, advertisers pay a sum of money to publishers, so the advertisements can appear on their websites [34]. When someone uses adblocking on their device, it can cut the income stream for publishers, which is precisely their main source of income [34]. Blocking advertisements can reduce advertising revenue for publishers [34]. In turn, it will reduce the ability of advertisers to invest in content presented on the website [34]. As a result, the website becomes less attractive to consumers, which ultimately reduces the traffic generated on the website, thereby further decreasing advertising revenue for publishers [34].

There are no ads displayed on a website, meaning there is no income from online advertising. Advertising blocking has a destructive effect on the digital advertising ecosystem [34]. Global estimated loss from using ad-blocking in 2013 were USD 7.2 Billion. In 2014 amounted to USD 11.7 Billion, and in 2015 amounted to USD 21.8 Billion [10]. In 2016, a global estimated loss from the use of ad-blocking was USD 41.4 Billion [10]. For Google, PageFair estimates that they have lost USD 6.6 Billion in global revenue due to the use of ad-blocking in 2014 [8].

Since 2011, an ad-blocking company named AdBlock Plus has created a whitelist that allows the presence of ads, even though the ad-blocking extension has been installed [35]. In October 2013, the AdBlock Plus company approved advertisements on 78 websites from 777 applicant websites, and in 2015, the number of whitelisted sites increased to 300 websites from 1500 applicant websites [35]. To be whitelisted, advertisements must transparently explain that they are real advertisements and may not interfere with website content [35]. AdBlock Plus companies see a business opportunity for a company that is considered large enough. AdBlock Plus will ask advertisers for payment if they want to be whitelisted [35]. In 2013, only 10\% of advertisers paid AdBlock Plus to be whitelisted, and in 2015, the amount was still the same [35]. One of the unnamed digital media companies will be charged $30 \%$ of their advertising revenue to be whitelisted by Eyeo and AdBlock Plus [35]. Attraction attracts advertisers, and blocking ads creates a new and exciting ecosystem [35].

If blocking ads damages the business model that supports online advertising, then what happens next is a market failure [36]. It is unavoidable for the website to generate revenue to cover its costs if ad-blocking is still happening [36]. Several digital publishers, including Wired, 
Forbes, and The Times, have begun experimenting with anti-blocking ad techniques, including asking visitors who use ad-blocking to whitelist their websites so that advertisements can still appear when visiting their website [4]. Another way is to politely ask users to disable ad-block on their device and explain that advertising is a way to support that website, so that content can still be enjoyed free of charge [21]. Websites like Guardian even introduce donation links for users who enable ad-block to keep their content open even though there is no income from advertisement [21]. What people read on a website on the internet is not free. Ad-block can also be a potential reason for job loss and loss of independent online media [21]. Mark Thompson emphasized this as president and chief executive of The Times, that enjoyed journalism costs real money and needs to be paid, and advertising is an important part of the revenue mix [4]. The main effect of using ad-block is on medium-size publishers who have a significant amount of traffic to be affected but do not have enough power to fight against ad-blocking. In addition to losing revenue, middle-size publishers also lose user data [21].

Facebook is aware of the disadvantages of ad-blocking, so Facebook is looking for ways to display ads better [4]. On August 9, 2016, Facebook announced changes to its website by "making all blocking ads useless" [4]. Facebook makes the code for ads, and the code for Newsfeed content similar, so that filter-based ad-blocking, which based on filters, cannot distinguish between ads and website content [19]. A few days later, AdBlock Plus, with EasyList updated its filter rules and stated that the confusion that Facebook was trying to create was imperfect [19]. Facebook does not stay idle and renew their ad markup [19]. AdBlock Plus still cannot block Facebook Newsfeed ads. The move to defeat this ad-blocker has an impact on a $22 \%$ growth in ad revenue on Facebook usage on the desktop, even though Facebook usage on the desktop is declining [19].

The increasing popularity of ad-blocking has led to various reform efforts in the online advertising industry to improve the way of advertising [13]. Another way to counter the use of ad-blocking is to use anti-ad-blocker. Many publishers have implemented an anti-adblocker, which is a JavaScript code that can detect or respond to the presence of an ad-blocker on the client-side [13]. Anti-ad-blocker generally forces users to whitelist websites or disable their adblockers altogether [13]. Ad-blocker tries to avoid anti-ad-blocker by removing JavaScript code snippets or by hiding annoying ad-block detection notifications [13]. For this purpose, adblocker again relies on crowdsourced filter lists such as Anti-Ad-block Killer and the removal list of Ad-block Warnings [13]. First, HTTP filter list rules block HTTP requests for downloading anti-ad-block scripts [13]. Second, HTML filter rules hide HTML elements that contain ad block detection notifications [13]. Anti-ad-blocker script consists of two main components, the first is a trigger, which detects the presence of an ad-blocker, by checking the presence or absence of advertisements [13]. Second, reaction, which can display ad-block detection messages or only report the results to the backend server [13].

Ad-blocking is currently struggling to compete with anti-ad-blockers caused by the challenge of manually analyzing anti-blocking JavaScript [13]. To block the anti-ad-blocking code through rewriting JavaScript or hiding the existence of ad-blocker through the hooking API [13]. Zhu's system (2018) can bypass most anti-ad-blocking without causing damage to the functionality of any website (except those with Javascript rewriting) [13]. To remain vigilant in the long run with pressure from publishers and advertisers, it is essential for ad-block needs to counteract anti-ad-block in a rapidly increasing technological arms race [13]. 


\section{Conclusion and Recommendation}

Advertising always follows the changing times, starting from trends, mindsets, and also changes in technology [37]. However, many challenges arise along with technological developments today [37]. Right now, consumers no longer easily trust advertising until the product is endorsed by people personally or by using positive words from mouth by a reliable source [37]. Word of mouth reviews and reviews by consumers have been recognized as a powerful marketing tool that can cut noise quickly and effectively, and instill trust among consumers [37]. Powerful effects in online social networks can significantly influence customer purchasing decisions through trust in electronic word of mouth marketing (eWOM) [38]. Word of mouth form can use the concept of endorsers. Endorsement is a form of advertising that uses well-known personalities that demand recognition, trust, and high respect among people [37]. Celebrity endorsers can be defined as any individual who enjoys public attention and uses that recognition for products and goods that appear with him in an advertisement [39]. Also, endorser credibility influences attitudes toward advertising, product perception, and product image [40]. The preferred level of an endorser can also create a powerful impact on consumers' thoughts about the item being advertised [41]. Endorsement can be done through social media such as Instagram [42], Twitter [43], and also YouTube [44], [45]. An example of the use of celebrity endorse on social media, such as Twitter, is on advertisements promoted by professional athletes. Four things that affect the endorsement of professional athletes on Twitter are sources of interest, expertise, level of trust, and congruence [46]. From previous research, it is known that social media such as Twitter is widely used by professional athletes to inform about personal life, sports-related matters or not related to sports, to shape self-image, and carry out promotions [43]. Professional athletes use various social media because they can provide real-time closeness and dialogue one by one with their fans [43]. The use of endorsers is closely related to the selection of figures; therefore using celebrity endorsers can be an alternative approach to advertising by targeting buyers more personally. Buyers will be more interested in who advertises it than what goods are advertised.

The use of ad-blocking is driven by unique problems such as the delivery of online advertising, and not the rejection of the advertisements themselves [23]. If the quality of online advertising is magnificent, then ad-blockers are no longer needed, although creating highquality advertising content requires resources, skills, energy, and time [30]. By increasing the relevance of advertising messages through personalization [37], advertisers can ensure that their advertisements not seen as distracting by their target market [47]. The future of advertising lies in advertising that can go beyond relationship focus to engagement focus [37]. Ad creators should not continue to blame ad-blockers and better change perspective and see opportunities to improve the quality of advertisements that will be offered [30]. Online advertising content must be fun and credible [48]. If online advertising is annoying, the target market will try to avoid being exposed to the ad [48]. However, if online advertisements are made exciting or fun, the target market will tend to be more willing to see these ads and even share them with friends [48].

It should be remembered that the pleasure caused by advertising is found to be the most influential antecedent in attitudes towards online advertising [48]. Besides, the number of advertisements received by each website user must also be limited by publishers [48]. One of them is by maintaining a balance between the amount of non-promotional content provided by the website [48]. If it exceeds the threshold of internet users, it will trigger negative attitudes towards certain websites and negative attitudes towards online advertising in general [48]. Another thing related to advertising is stakeholders must improve the reputation of online 
advertising through a massive education campaign. This campaign can spread a greater and deeper awareness about the economic benefits represented by online advertising for the media, consumers, markets, companies, industries, economy, and society as a whole [48].

The tug-of-war between ad-block and advertisements will continue to exist. It will never die, as long as online advertising forms keep to interfere and force internet users. Despite the difficulties and challenges, the advertising industry must have the courage to offer internet users an alternative to the use of ad-blocking [34]. The offer from this advertiser must be considered valuable from their perspective and must also consider the expectations and preferences of users [34]. Fresh ideas and advertisements in exciting new forms should be the best way today. Basically, people don't hate ads; they hate lousy user experiences [30]. The shift from invading and disturbing advertisements can be diverted to advertising by using word of mouth using endorsers on social media. If the innovation of the advertiser fails to fight the ad-blocker, and all users start using the ad-blocking feature, then online advertising will not develop much [1]. A world without advertising will offer limited scope of goods, services, and entertainment [49].

\section{References}

[1] A. Tiwary, Know Online Advertising: All Information About Online Advertising at One Place. Partridge Publishing India, 2016.

[2] L.-F. Lin, Y.-M. Li, and W.-H. Wu, "A social endorsing mechanism for target advertisement diffusion," Inf. Manag., vol. 52, no. 8, pp. 982-997, Dec. 2015.

[3] D. Patten, How to market your business : a practical guide to advertising, PR, selling, and direct and online marketing, 6th ed. Kogan Page Publishers, 2008.

[4] M. Isaac, "Facebook Blocks Ad Blockers, but It Strives to Make Ads More Relevant," 2016. [Online]. Available: https://www.nytimes.com/2016/08/10/technology/facebook-ad-blockers.html. [Accessed: 24-Mar-2019].

[5] P. Hanafizadeh, Online Advertising and Promotion: Modern Technologies for Marketing. Business Science Reference, 2012.

[6] A. K. Singh and V. Potdar, "Blocking online advertising - A state of the art," in Proceedings of the IEEE International Conference on Industrial Technology, 2009.

[7] E. L. Post and C. N. Sekharan, "Comparative study and evaluation of online ad-blockers," in 2015 IEEE 2nd International Conference on InformationScience and Security, ICISS 2015, 2016.

[8] L. O'Reilly, "The inventor of Adblock tells us he wrote the code as a 'procrastination project' at university, and he's never made money from it," Business Insider, 2015. [Online]. Available: https://www.businessinsider.com/interview-with-the-inventor-of-the-ad-blocker-henrik-aastedsrensen-2015-7/?IR=T. [Accessed: 24-Mar-2019].

[9] "Millennials at the Gate," Anatomy Media, Inc., New York, 2016.

[10] PageFair and Adobe, "The cost of ad blocking. 2015 Ad Blocking Report," 2015.

[11] A. A. Tudoran, "Why do internet consumers block ads? New evidence from consumer opinion mining and sentiment analysis," Internet Res., vol. 29, no. 1, pp. 144-166, Feb. 2018.

[12] Ad Lightning, “Ad Quality Report Q1 2017,” 2017.

[13] S. Zhu, X. Hu, Z. Qian, Z. Shafiq, and H. Yin, "Measuring and Disrupting Anti-Adblockers Using Differential Execution Analysis," in Proceedings 2018 Network and Distributed System Security Symposium, 2016.

[14] Y. Yuan, J. P. Caulkins, and S. Roehrig, "The relationship between advertising and content provision on the Internet,” Eur. J. Mark., vol. 32, no. 7/8, pp. 677-687, Aug. 1998.

[15] M. P. Johnston, Secondary Data Analysis: A Method of which the Time Has Come, vol. 3. 2014.

[16] P. Juneja, "Desk Research - Methodology and Techniques," Management Study Guide, 2020. [Online]. Available: https://www.managementstudyguide.com/desk-research.htm. [Accessed: 08-Jan2020].

[17] N. Smyth, Ad Blocking Survival Guide: Tactics and Strategies for Web Publishers. CreateSpace 
Independent Publishing Platform, 2016.

[18] PageFair, "How does adblock work?," PageFair, 2017. [Online]. Available: https://pagefair.com/intel/. [Accessed: 23-Mar-2019].

[19] G. Storey, D. Reisman, J. Mayer, and A. Narayanan, "The Future of Ad Blocking: An Analytical Framework and New Techniques," May 2017.

[20] C. E. Wills and D. C. Uzunoglu, "What Ad Blockers Are (and Are Not) Doing," in 2016 Fourth IEEE Workshop on Hot Topics in Web Systems and Technologies (HotWeb), 2016, pp. 72-77.

[21] E. Rudneva, "Influence of Adblockers on the Future of Mobile Advertising Industry," Saimaa University of Applied Sciences, 2017.

[22] M. Rosenwald, "The digital media industry needs to react to ad blockers ... or else," Columbia Journalism Review, 2015. [Online]. Available: https://www.cjr.org/business_of_news/will_ad_blockers_kill_the_digital_media_industry.php.

[Accessed: 22-Mar-2019].

[23] PageFair, "The State of the Blocked Web: 2017 Global Adblock Report," 2017.

[24] J. Mander and C. Beer, "Ad Blocking Trends Report 2018," GlobalWebIndex, 2018.

[25] J. Plummer, S. Rappaport, T. Hall, and R. Barocci, THE ONLINE ADVERTISING PLAYBOOK. Proven Strategies and Tested Tactics from The Advertising Research Foundation. Hoboken, New Jersey: John Wiley \& Sons, Inc., 2007.

[26] T. H. Baek and M. Morimoto, "Stay Away From Me. Examining the Determinants of Consumer Avoidance of Personalized Advertising," J. Advert., vol. 41, no. 1, pp. 59-76, Apr. 2012.

[27] P. S. Speck and M. T. Elliott, "Predictors of advertising avoidance in print and broadcast media," J. Advert., vol. 26, no. 3, pp. 61-76, Oct. 1997.

[28] C. H. Cho and H. J. Cheon, "Why do people avoid advertising on the internet?," J. Advert., vol. 33, no. 4, pp. 89-97, Dec. 2004.

[29] J. Tang, P. Zhang, and P. F. Wu, "Categorizing consumer behavioral responses and artifact design features: The case of online advertising," Inf. Syst. Front., vol. 17, no. 3, pp. 513-532, Jun. 2015. [30] O. Tunikova, "The Real Effect Ad Blocking Has on Publishers and Advertisers," Medium, 2018. [Online]. Available: https://medium.com/@tunikova_k/the-real-effect-ad-blocking-has-on-publishersand-advertisers-7bf1b72be237. [Accessed: 22-Mar-2019].

[31] P. W. J. Verlegh, M. L. Fransen, and A. Kirmani, "Persuasion in advertising: When does it work, and when does it not?," Int. J. Advert., vol. 34, no. 1, pp. 3-5, Jan. 2015.

[32] N. Vratonjic, M. H. Manshaei, J. Grossklags, and J.-P. Hubaux, "Ad-Blocking Games: Monetizing Online Content Under the Threat of Ad Avoidance," in The Economics of Information Security and Privacy, vol. 273, no. 23, Berlin, Heidelberg: Springer Berlin Heidelberg, 2013, pp. 4973.

[33] J. Mander, F. McGrath, C. Buckle, and K. Young, "Indonesia GWI Market Report Q4 2016," GlobalWebIndex: London, 2016.

[34] J. Wielki and J. Grabara, "The Impact of Ad-Blocking on the Sustainable Development of the Digital Advertising Ecosystem," Sustainability, vol. 10, no. 11, p. 4039, Nov. 2018.

[35] M. Geuss, "Over 300 businesses now whitelisted on AdBlock Plus, 10\% pay to play," ars Technica, 2015. [Online]. Available: https://arstechnica.com/information-technology/2015/02/over300-businesses-now-whitelisted-on-adblock-plus-10-pay-to-play/. [Accessed: 22-Mar-2019].

[36] B. Shiller, J. Waldfogel, and J. Ryan, "The effect of ad blocking on website traffic and quality," RAND J. Econ., vol. 49, no. 1, pp. 43-63, Mar. 2018.

[37] V. Kumar and S. Gupta, "Conceptualizing the Evolution and Future of Advertising," J. Advert., vol. 45, no. 3, pp. 302-317, Jul. 2016.

[38] S. Liu, C. Jiang, Z. Lin, Y. Ding, R. Duan, and Z. Xu, "Identifying effective influencers based on trust for electronic word-of-mouth marketing: A domain-aware approach," Inf. Sci. (Ny)., vol. 306, pp. 34-52, 2015.

[39] G. McCracken, "Who is the Celebrity Endorser? Cultural Foundations of the Endorsement Process," J. Consum. Res., vol. 16, no. 3, p. 310, 2002.

[40] C. Atkin et al., "Effectiveness of Celebrity Endorsers," J. Advert. Res., 1983.

[41] C. Tripp, T. D. Jensen, and L. Carlson, "The Effects of Multiple Product Endorsements by 
Celebrities on Consumers' Attitudes and Intentions," J. Consum. Res., vol. 20, no. 4, p. 535, Mar. 2002. [42] L. Setiawan, "Pengaruh Celebrity Endorsement terhadap Purchase Intention dengan Brand Awareness sebagai Variabel Mediasi pada Produk Green Tea Esprecielo Allure," J. Manaj. Pemasar., vol. 12 , no. 1 , pp. 53-60, 2018.

[43] G. Abeza, N. O’Reilly, B. Séguin, and O. Nzindukiyimana, "The world's highest-paid athletes, product endorsement, and Twitter," Sport. Bus. Manag. An Int. J., vol. 7, no. 3, pp. 332-355, Jul. 2017.

[44] C. Gerhards, "Product placement on YouTube: An explorative study on YouTube creators' experiences with advertisers," Converg. Int. J. Res. into New Media Technol., p. 135485651773697, Oct. 2017.

[45] C. Schwemmer and S. Ziewiecki, "Social Media Sellout: The Increasing Role of Product Promotion on YouTube," Soc. Media + Soc., vol. 4, no. 3, p. 205630511878672 , Jul. 2018.

[46] N. Cunningham and L. F. Bright, "The tweet is in your court: Measuring attitude towards athlete endorsements in social media," Int. J. Integr. Mark. Commun., vol. 4, no. 2, pp. 73-87, 2012.

[47] S. M. Edwards, H. Li, and J.-H. Lee, "Forced Exposure and Psychological Reactance: Antecedents and Consequences of the Perceived Intrusiveness of Pop-Up Ads," J. Advert., 2013.

[48] I. Redondo and G. Aznar, "To use or not to use ad blockers? The roles of knowledge of ad blockers and attitude toward online advertising," Telemat. Informatics, vol. 35, no. 6, pp. 1607-1616, Sep. 2018.

[49] J. Sivulka, Soap, Sex, and Cigarettes. A Cultural History of American Advertising, 2nd ed. Boston: Wadsworth, Cengage Learning, 2012. 